\title{
The location and rate of dayside reconnection during an interval of southward interplanetary magnetic field
}

\author{
M. Pinnock ${ }^{1}$, G. Chisham ${ }^{1}$, I. J. Coleman ${ }^{1}$, M. P. Freeman ${ }^{1}$, M. Hairston ${ }^{2}$, and J.-P. Villain ${ }^{3}$ \\ ${ }^{1}$ British Antarctic Survey, Natural Environment Research Council, High Cross, Madingley Road, Cambridge, CB3 0ET, UK \\ ${ }^{2}$ Center for Space Sciences, Univ. of Texas at Dallas, Richardson, Texas, USA \\ ${ }^{3}$ LPCE/CNRS, 3A Av. De la Recherche Scientifique, 45071 Orleans Cedex, France
}

Received: 27 August 2002 - Revised: 9 January 2003 - Accepted: 11 February 2003

\begin{abstract}
Using ionospheric data from the SuperDARN radar network and a DMSP satellite we obtain a comprehensive description of the spatial and temporal pattern of dayside reconnection. During a period of southward interplanetary magnetic field (IMF), the data are used to determine the location of the ionospheric projection of the dayside magnetopause reconnection X-line. From the flow of plasma across the projected $\mathrm{X}$-line, we derive the reconnection rate across $7 \mathrm{~h}$ of longitude and estimate it for the total length of the Xline footprint, which was found to be $10 \mathrm{~h}$ of longitude. Using the Tsyganenko 96 magnetic field model, the ionospheric data are mapped to the magnetopause, in order to provide an estimate of the extent of the reconnection X-line. This is found to be $\sim 38 R_{E}$ in extent, spanning the whole dayside magnetopause from dawn to dusk flank. Our results are compared with previously reported encounters by the Equator-S and Geotail spacecraft with a reconnecting magnetopause, near the dawn flank, for the same period. The SuperDARN observations allow the satellite data to be set in the context of the whole magnetopause reconnection X-line. The total potential associated with dayside reconnection was $\sim 150 \mathrm{kV}$. The reconnection signatures detected by the Equator-S satellite mapped to a region in the ionosphere showing continuous flow across the polar cap boundary, but the reconnection rate was variable and showed a clear spatial variation, with a distinct minimum at 14:00 magnetic local time which was present throughout the 30-min study period.
\end{abstract}

Key words. Magnetospheric physics (magnetopause, cusp and boundary layers; magnetosphere-ionoshere interactions) - Space plasma physics (magnetic reconnection)

\section{Introduction}

Understanding the transfer of solar wind momentum and plasma across the boundary of the dayside magnetopause is of prime importance in quantifying the impact of the solar

Correspondence to: M. Pinnock (M.Pinnock@bas.ac.uk) wind on the Earth's magnetosphere. While a good qualitative understanding of the processes involved has been achieved, considerable progress is still required before it can be reliably modeled and used for predictive purposes in applications such as space weather forecasting. Most of the studies of the rate of momentum transfer have been performed at a single point on the magnetopause (e.g. Sonnerup et al., 1981) or in the ionosphere (e.g. de la Beaujardière et al., 1991). Limited spatial coverage of the $\mathrm{X}$-line has been achieved in some studies, for example, over a 2-h segment of the ionosphere (Baker et al., 1997). In this paper we report observations that encompass $\sim 70 \%$ of the dayside merging region, with a time resolution of 2 minutes, using ionospheric techniques.

The rate of magnetic reconnection in geospace is best monitored in the ionosphere. A snapshot measurement insitu, at the reconnection $\mathrm{X}$-line, can be made, but prolonged measurement is practically impossible due to our lack of knowledge of where the X-lines are, the variability in their position and the inability to keep a spacecraft there. At present, it is only in the ionosphere, where the cusp magnetic field topology causes dayside magnetopause phenomena to be focused in 3-6 hours of magnetic local time (Crooker and Toffoletto, 1995), that the area containing the footprint of the X-line (the merging line) can be monitored continuously. Traditionally, the reconnection rate has been measured in the ionosphere by the potential difference across the open field line region in the dawn-dusk meridian using polar orbiting spacecraft (Reiff et al., 1981). These measurements are limited by their 1-D orbital trajectory (that does not always intercept the ends of the projected X-line) and their low resolution in time due to the $\sim 100$-min spacecraft orbit. Such a sampling rate means that they cannot capture transient and localised reconnection phenomena that have been reported from ground-based experiments (e.g. Neudegg et al., 1999).

More recently, improved resolution has come from using a network of magnetometers, radars and spacecraft to construct the electric potential distribution across much of the high-latitude ionosphere and has provided useful information 


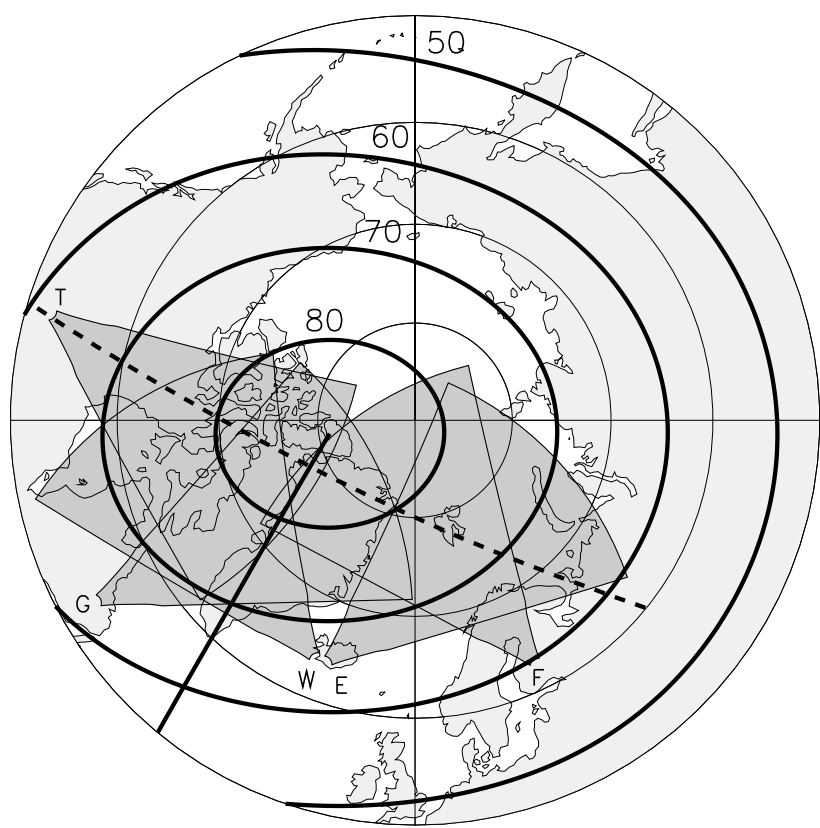

Fig. 1. Geographic map showing the fields-of-view of the five SuperDARN radars used in the study. Geomagnetic latitudes from 50 to $80^{\circ}$ latitude are shown with bold lines, the faint lines show geographic latitude over the same latitude range. The transit of the DMSP F13 satellite between 13:24 and 13:38 UT is shown by the dashed line. The bold magnetic meridian line (bottom left quadrant of the figure) marks magnetic noon at 13:30 UT.

on the large-scale ionospheric convection (e.g. Ridley et al., 1997). Even so, some uncertainties arise from the magnetometer inversion method and spatial interpolation. Furthermore, measurement of the ionospheric electric field alone is not sufficient to measure the dayside and nightside reconnection rates. To measure the reconnection rate it is necessary to identify the ionospheric projection of the dayside and nightside $\mathrm{X}$-lines and measure the potential differences along them in their rest frame (e.g. Freeman and Southwood, 1988; de la Beaujardière et al., 1991). It is expected that the footprints of the X-lines vary in location on a time scale of minutes and by many 10 s of kilometres (Cowley and Lockwood, 1992), hence the need to reference the plasma flows to the rest frame of the X-lines. To achieve this measurement is difficult, as it usually requires a conjunction of at least two observing instruments; one to determine the footprint of the $\mathrm{X}$-line and a second to measure the plasma flow. Blanchard et al. (2001) have shown how a single incoherent scatter radar can be used to measure the reconnection rate at a single meridian. Studies by Baker et al. (1997) and Pinnock et al. (1999) demonstrated the ability of the radars of the Super Dual Auroral Radar Network (SuperDARN) to perform the measurement, the greater field of view of a single SuperDARN radar extending the coverage to $\sim 2 \mathrm{~h}$ of MLT. Global auroral images can also be used as a proxy for the polar cap boundary and the expansion and contraction of the polar cap area monitored through the substorm cycle (e.g. Brittnacher et al., 1999). If combined with plasma flow measurements, then the reconnection rate could be estimated.

Phan et al. (2000) reported observations by the Geotail and Equator-S satellites of bi-directional plasma jets in the dawnside low-latitude magnetopause, during a period of southward IMF. The repeated encounters with the jets over more than one hour indicated that reconnection was active much of the time, with its site remaining quasi-stationary near the equator. They argued for the existence of a stable and extended reconnection X-line spanning the entire dayside magnetopause. Partial confirmation of this hypothesis was provided by Phan et al. (2001), which used SuperDARN radar data from the noon sector to confirm that subsolar reconnection was occurring in the same period.

In this paper we use a network of the Northern Hemisphere SuperDARN radars and an overpass of the Defense Meteorological Satellite Program (DMSP) F13 satellite (see Fig. 1) to investigate the dayside reconnection rate across a wide longitudinal range $(\sim 7 \mathrm{~h}$ of MLT). Using a magnetic field model, the ionospheric footprint of the reconnection X-line is mapped to the magnetopause surface. From this we determine where, and at what rate, reconnection occurs on the magnetopause with an unprecedented spatial coverage and resolution. This allows us to place the Phan et al. (2000, 2001) observations in the context of the whole dayside magnetopause reconnection rate. We find evidence for one of the longest reconnection X-lines ever reported.

\section{Observations}

\subsection{Event overview}

Figure 2 shows the IMF observed by the Wind (light line) and IMP-8 (dark line) spacecraft, the solar wind dynamic pressure measured by Wind, and the $A U$ and $A L$ auroral electrojet indices, for the period 12:30 to 15:00 UT on 11 February 1998. The Wind spacecraft position at 13:30 UT was $X=235.4 R_{E}, Y=2.2 R_{E}, Z=-31.4 R_{E}$ in geocentric solar magnetospheric (GSM) coordinates. Its data have been lagged by $60 \mathrm{~min}$ to give the best correlation with the data from IMP-8, whose position at 13:30 UT was $X=11.8 R_{E}$, $Y=-29.4 R_{E}, Z=0.3 R_{E}$ in GSM coordinates. The IMF $B_{z}$ component became negative at $\sim 12: 00$ UT (at the IMP-8 spacecraft) and remained negative until $\sim 15: 00 \mathrm{UT}$, although there are some brief (few minutes), localized (i.e. only seen at IMP-8 or Wind) excursions to $B_{z}$ positive (e.g. at 13:35 UT). IMF $B_{y}$ is close to zero until 14:25 UT, when it trends to $\sim-6 \mathrm{nT}$ at 15:00 UT. IMF $B_{x}$ is $\sim 4 \mathrm{nT}$ throughout, with some short-lived, localized, excursions to zero or negative values. Although there is evidence for some structure in the solar wind, this is relatively short lived. The period between 13:30 and 14:00 UT (vertical lines in Fig. 2) studied in this paper is thus best characterized by purely southward IMF.

The solar wind dynamic pressure was fairly typical at $\sim 1.6 \mathrm{nPa}$ until $13: 55 \mathrm{UT}$ and then increased to $\sim 2 \mathrm{nPa}$. In 
the period from 13:30 to 13:55 UT the variability in the pressure was typically not greater than $20 \%$.

The $A L$ electrojet index shows steadily increasing activity through the period. Particle flux data from the Los Alamos National Laboratory (LANL) 1994-84 spacecraft (not shown), in the 20:00 MLT sector at 13:30 UT, show no clear substorm particle injection signature until $~ 16: 25$ UT. A weak, low electron energy particle injection signature was observed by the LANL 1997A satellite at $~ 15: 00$ UT in the 19:00 MLT sector. However, the magnetogram from College, Alaska (not shown), at 22:40 MLT at 13:30 UT, shows a $500 \mathrm{nT}$ negative bay in the $\mathrm{H}$ component commencing at 13:24 UT and peaking at 14:05 UT. The onset of the bay is very rapid and typical of that associated with a substorm onset.

The Northern Hemisphere SuperDARN radars had their best scatter conditions in the interval 13:30 to 14:00 UT, so this forms the core time of this study.

\subsection{Deriving convection maps from SuperDARN radars}

SuperDARN is a network of coherent scatter high frequency (HF) radars (Greenwald et al., 1995) which measure backscatter from field-aligned, decameter-scale ionospheric irregularities. SuperDARN's primary aim is to study the global ionospheric convection pattern at high latitudes. Subject to achieving the backscatter condition, each radar can image $2-3 \mathrm{~h}$ of magnetic local time in the region of the polar cap boundary. The radars measure, in the F-region, the line-of-sight plasma velocity drift (Villain et al., 1985; Ruohoniemi et al., 1987) and its spectral characteristics. The fields-of-view of the radars used in this study are shown in Fig. 1; this study predates the deployment of all 9 radars now operating in the Northern Hemisphere.

Many of the SuperDARN radars have overlapping fieldsof-view which allow the estimation of unambiguous fieldperpendicular velocity vectors, by combining coincident line-of-sight velocity measurements. However, overlapping scatter is not always present, so to maximize the use of all available line-of-sight data, the technique of global convection mapping (Ruohoniemi and Baker, 1998) was developed.

SuperDARN global convection maps are produced by fitting line-of-sight velocity data from the radars to an expansion of an electrostatic potential function, expressed in terms of spherical harmonics. Prior to this fitting process, radar data which are identified as groundscatter or which do not exceed a certain minimum velocity (typically $35 \mathrm{~m} / \mathrm{s}$ ) or signalto-noise ratio (typically $3 \mathrm{~dB}$ ) are removed. This filtering process can sometimes fail to reject line-of-sight velocity data which do not relate to the convection electric field, e.g. ground scatter mixed with ionospheric scatter or E-region scatter which is limited to the ion acoustic velocity. Additional techniques have been developed to ensure that these are removed (Chisham and Pinnock, 2002) and are employed here. The remaining line-of-sight velocity data are spatially and temporally median filtered. These data are then mapped

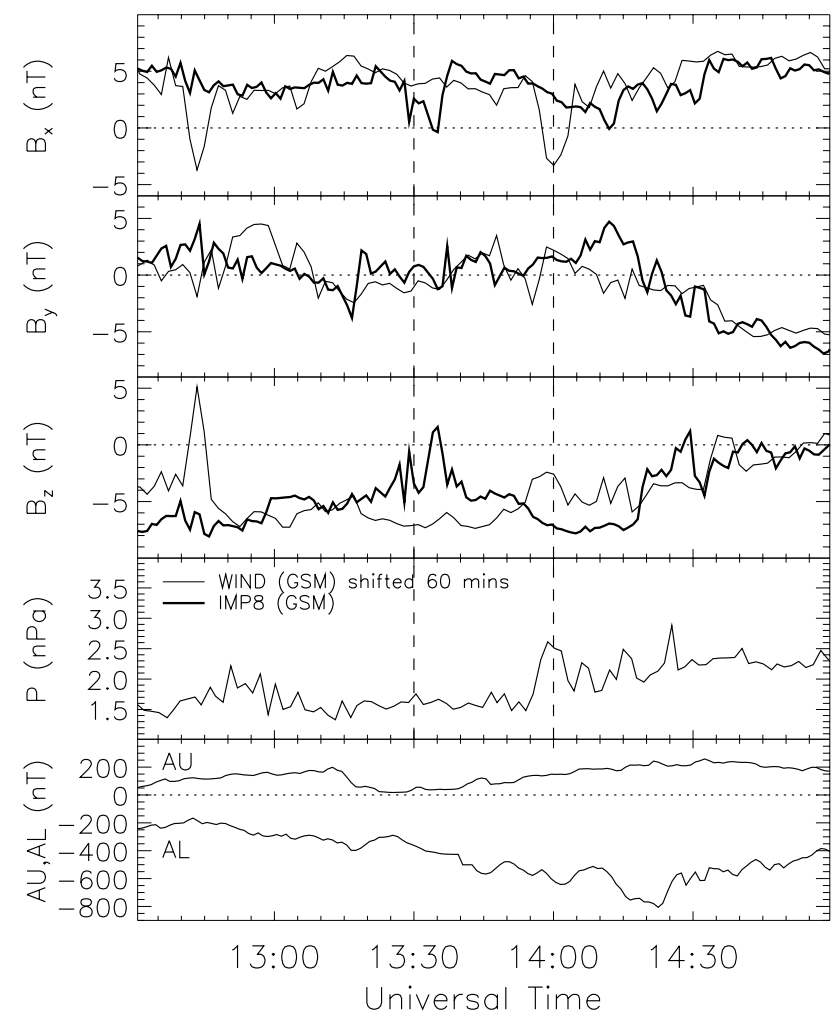

Fig. 2. Overview of the geophysical conditions on 11 February 1998. The dashed vertical lines in each panel mark the period of the reconnection analysis. The top three panels show the interplanetary magnetic field measured by the Wind (faint line) and IMP-8 (bold line) spacecraft. The Wind data have been lagged $60 \mathrm{~min}$ in time to allow for the propagation time from Wind to IMP-8 (see text for position of the spacecraft). The fourth panel shows the solar wind dynamic pressure determined from Wind data, lagged by 60 min. The fifth panel shows the $A U$ and $A L$ indices for the period.

on to a geomagnetic coordinate grid encompassing the polar region (see Ruohoniemi and Baker, 1998 for full details).

In this study, the radar data have been supplemented with the along- and across-track plasma drift velocities from the DMSP F13 satellite (Retarding Potential Analyzer (RPA) and Ion Drift Meter instruments, respectively). The satellite traversed the northern polar cap between 13:24 and 13:37 UT (see Fig. 1) and went from 17:00 MLT to 06:00 MLT, reaching a peak geomagnetic latitude of $85^{\circ} \mathrm{N}$. The Altitude Adjusted Corrected Geomagnetic (AACGM) coordinate system, a development of the Polar Anglo-American Conjugate Experiment geomagnetic coordinate system of Baker and Wing (1989), is used throughout this study. The satellite plasma drift data taken during each two-minute radar scan period have been processed using the same median filtering and gridding technique as described in Ruohoniemi and Baker (1998), combined with the radar data, and the potential mapping solution obtained. The DMSP data provide valuable additional information, particularly in the 06:00 MLT sector, where almost no radar scatter exists. The DMSP drift data have been examined carefully to remove corrupt 
Velocity $(\mathrm{m} / \mathrm{s})$
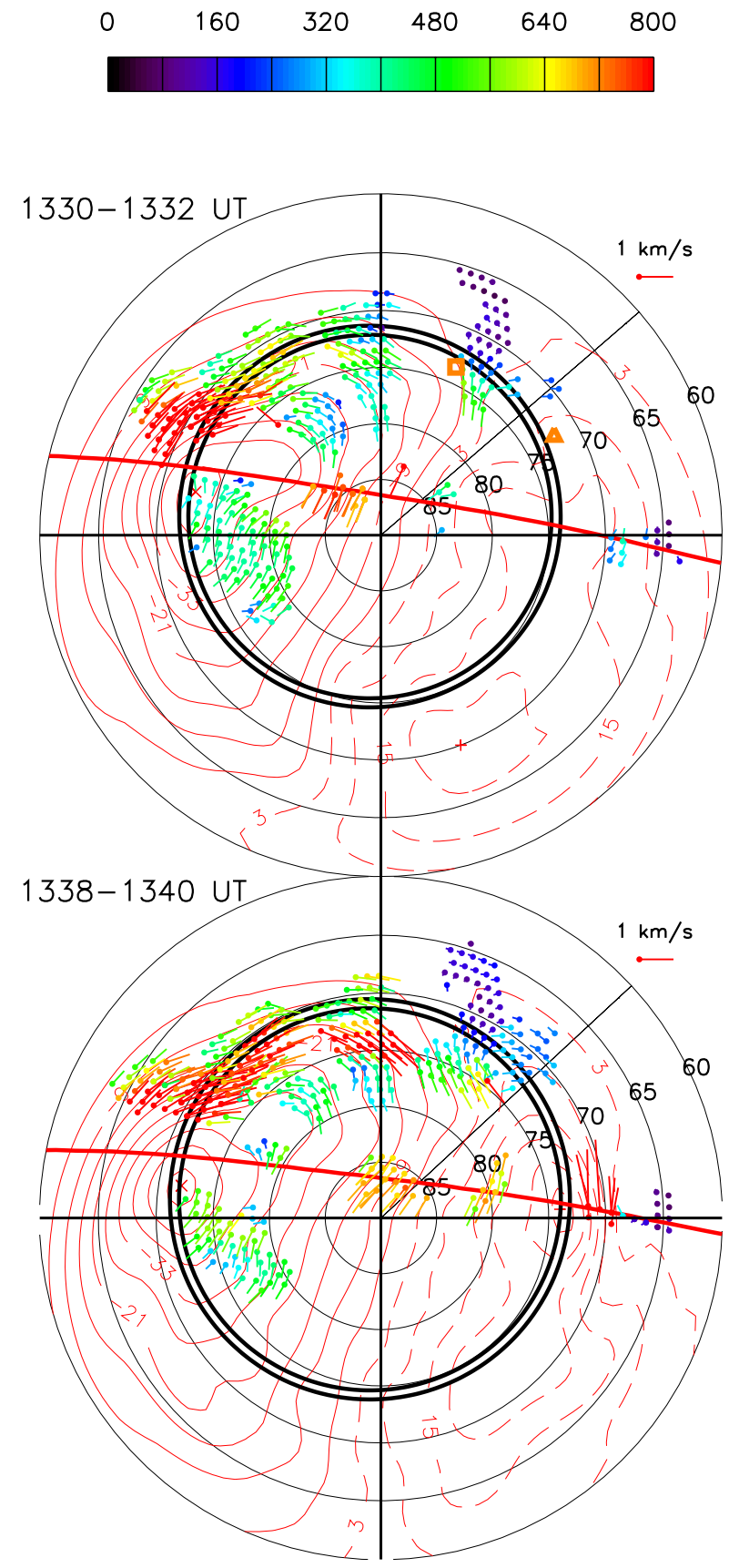

Fig. 3. Samples of the SuperDARN equipotential contour maps for two periods, with radar determined "true vectors" and satellite plasma drift vectors overlaid, both colour-coded according to magnitude. The path of the DMSP F13 satellite in the interval from 13:24 to 13:38 UT is shown by the red line. The orange square and triangle in Fig. 3a mark the location to which the Equator-S and Geotail satellites map at 13:30 UT, respectively. The longitude line in the upper right quadrant of each picture marks the $0^{\circ} \mathrm{E}$ location.

data. In particular, data from below 62 degrees latitude in the 06:00 MLT sector were invalid because the plasma den- sity was too low to give reliable values. Also, examination of the RPA current and voltage curves showed that in the interval between $69^{\circ}$ and $65^{\circ} \mathrm{N}$ geomagnetic latitude in the 06:00 MLT sector some data points were not of good enough quality to give reliable values. These too have been removed from our analysis. Finally, the drift data (measured in the inertial reference frame) are translated to the corotating frame (the same reference frame as the radar data) before being combined with the radar data.

To constrain the solution effectively in regions where little or no radar or satellite data are available, a statistical model (Ruohoniemi and Greenwald, 1996) is used to augment the data. The choice of statistical model is based on the prevailing IMF conditions and, although having some influence on the global solution, generally has little influence on the solution in regions where data exist (Shepherd and Ruohoniemi, 2000). The fitting is then performed on the combined data set and the best fit determined by a least-squares method. The fitting is dependent on the following user-selected parameters: (1) the order of the spherical harmonic fit, and (2) the spatial extent over which the fit is performed. Higher order fits reproduce better mesoscale features of the convection and reduce the uncertainty of the fit, but are more computationally intensive. In this study 11 th order fits have been used. Changing the spatial extent of the fitting can change the global nature of the solution but rarely has a significant effect on mesoscale variations. The solution provides an estimate of the convection electric field across the polar region of the ionosphere and can be used to study its large-scale characteristics (e.g. the cross-polar cap potential, Shepherd and Ruohoniemi, 2000) or its mesoscale features (e.g. flow vortices, convection reversal boundaries).

The solution is good in regions where radar backscatter exists but one must be careful in reaching conclusions from areas were the flows are mainly determined by the statistical convection model. For this reason, we only derive the reconnection rate at longitudes where radar data are present. The plasma flow vectors used in this study are termed "true vectors"; they are derived from the radar line-of-sight velocity measurement, combined with the velocity component transverse to the radar beam, which is derived from the equipotential contour pattern given by the convection fitting process (see Chisham et al., 2002, Appendix A). Provan et al. (2002) showed that the "true vectors" are a better estimate of the magnitude of the flow than are "fitted" vectors (which are determined solely from the potential contour map).

Figure 3 shows two sample convection patterns, for the intervals, 13:30-13:32 UT (Fig. 3a) and 13:38-13:40 UT (Fig. 3b). In these plots the radar scatter exists wherever a radar "true vector" is plotted. Note that vectors shown as located on the path of the DMSP F13 satellite (red line) are from its ion drift data. In the 13:30-13:32 UT pattern these are located between 82 and $86^{\circ} \mathrm{N}$ latitude in the 15:00 MLT sector; in the 13:38-13:40 UT pattern they are located between 69 and $72^{\circ} \mathrm{N}$ latitude in the 06:00 MLT sector. Outside these regions only the equipotential contours derived from the data fitting process are shown. The quality of the global 


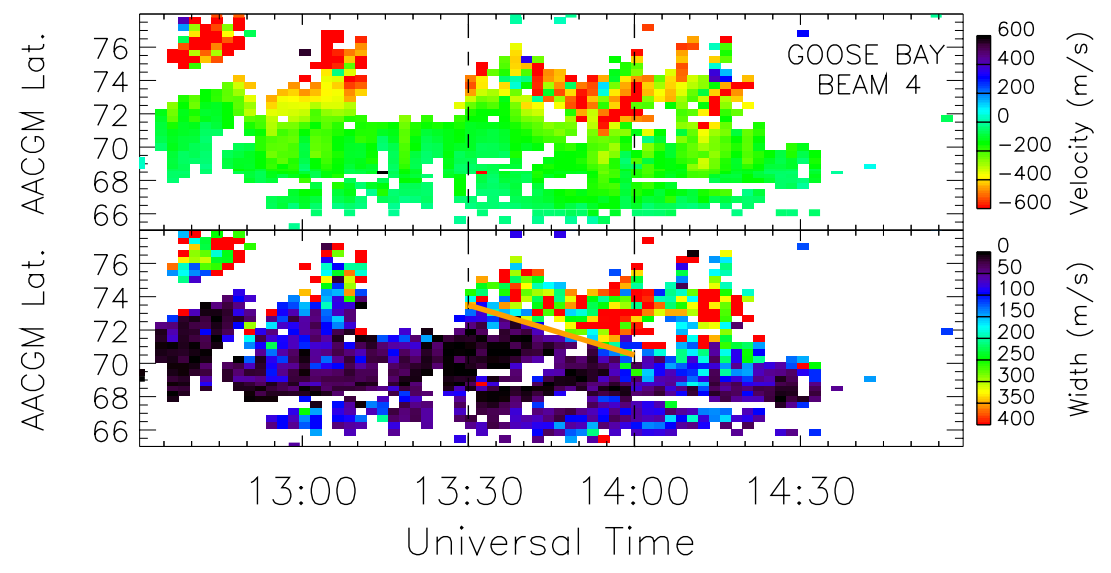

Fig. 4. The two panels show the lineof-sight Doppler velocity (upper panel) and the Doppler spectral width (lower panel) measured by the Goose Bay radar on beam 4 (aligned with the magnetic meridian). The orange sloping line on the lower panel marks the equatorward movement of the boundary between high and low spectral widths. convection pattern fit to the radar and satellite data is measured by a chi-squared parameter. The values for this are 0.9 and 1.3 for the 13:30-13:32 UT and 13:38-13:40 UT periods, respectively, values that are usually taken as representing a good fit (Ruohoniemi and Baker, 1998, p 20 803).

\subsection{Locating the Polar Cap Boundary (PCB)}

Accurately locating the ionospheric footprint of the magnetopause (the polar cap boundary) presents the greatest difficulty in any attempt to measure the reconnection rate. Lockwood (1997) and Rodger (2000) have drawn attention to the uncertainties involved in using ionospheric proxies for the PCB on the dayside, such as convection reversal, particle precipitation and auroral emission boundaries.

In this study, the location of the polar cap boundary for the period around 13:30 UT is found using satellite data near the dawn and dusk meridians and radar data from the pre-noon sector. In order to extrapolate the PCB to all dayside longitudes, a circle is fitted to these 3 points, which is the simplest continuous, closed shape that can connect them. Then, the radius of this circular $\mathrm{PCB}$ is incremented linearly with time between 13:30 and 14:00 UT, to agree with the linear latitudinal motion of the PCB in the pre-noon sector detected by the radar (see below). This provides a PCB location to be used with the plasma flow vectors derived every two minutes.

The assumption that the arc of a circle can approximate the PCB across the local time sector spanned by the radar and satellite data (06:00-17:00 MLT) and over the 30-min interval of interest is justified by reference to previous observations of the poleward boundary of the auroral oval that is a proxy for the PCB. Holzworth and Meng (1975), in deriving a mathematical expression for the Feldstein (1963) statistical oval, found that the poleward boundary of the auroral oval is approximated to zero order by a circle offset from the magnetic pole, for all geomagnetic activity levels. They verified this conclusion using quiet time (i.e. absence of substorms) DMSP satellite auroral images. Higher order components were found, but the magnitude of these perturbations on the dayside gives a maximum tilt of the PCB of the order of 10 degrees with respect to the zero order circle (see Pinnock et al., 1999, p. 447 for discussion of this), which results in an error of $<20 \%$ in determining the reconnection electric field for a flow vector of any magnitude within $\pm 45^{\circ}$ of the normal to the assumed circular PCB. Significant perturbations of the auroral oval shape are found for IMF $B_{z}$ northward (Hones et al., 1989), significant IMF $B_{y}$ component, and after substorm onset (Frank and Craven, 1988). Such conditions are absent during the study presented here, which takes place after $90 \mathrm{~min}$ of steady $B_{z}$ southward with nearly zero IMF $B_{y}$ component, in an interval of steadily increasing $A L$ index consistent with a growing DP2 current system, and with no substorm particle injections observed by geosynchronous satellites. These substorm growth phase conditions are optimal for observing a poleward boundary of the dayside auroral oval that approximates a circle (e.g. examples shown in Brittnacher et al., 1999).

In regions (e.g. dusk sector) where the flow vector is not within $45^{\circ}$ of normal to the assumed circular PCB it should be borne in mind that the radar's "true vectors" include a lineof-sight velocity measurement (from a single radar beam) that is very close to orthogonal to the PCB and thus provides a direct measurement (rather than a derived one) of the component critical for the reconnection electric field value. This point is returned to in Sect. 2.5.1; the use of more zonal pointing radar beams is shown to significantly underestimate the reconnection electric field.

The location of the boundary and the inflation rate of the polar cap have been fixed in the $\sim 10: 30$ MLT sector, using the Doppler spectral width characteristics of the Goose Bay radar backscatter. The equatorward edge of radar scatter showing large Doppler spectral widths, termed the spectral width boundary (SWB), has been shown to be coincident with the equatorward edge of the cusp particle precipitation (Baker et al., 1990, 1995) for a southward interplanetary magnetic field (IMF). André et al. (1999) have identified the cause of this large Doppler spectral width as due to the intense Pc1 wave activity present in the cusp.

The Goose Bay radar data from beam 4, aligned along the magnetic meridian, is shown in Fig. 4. This shows a mixture of ground scatter (low velocity (green) and low 

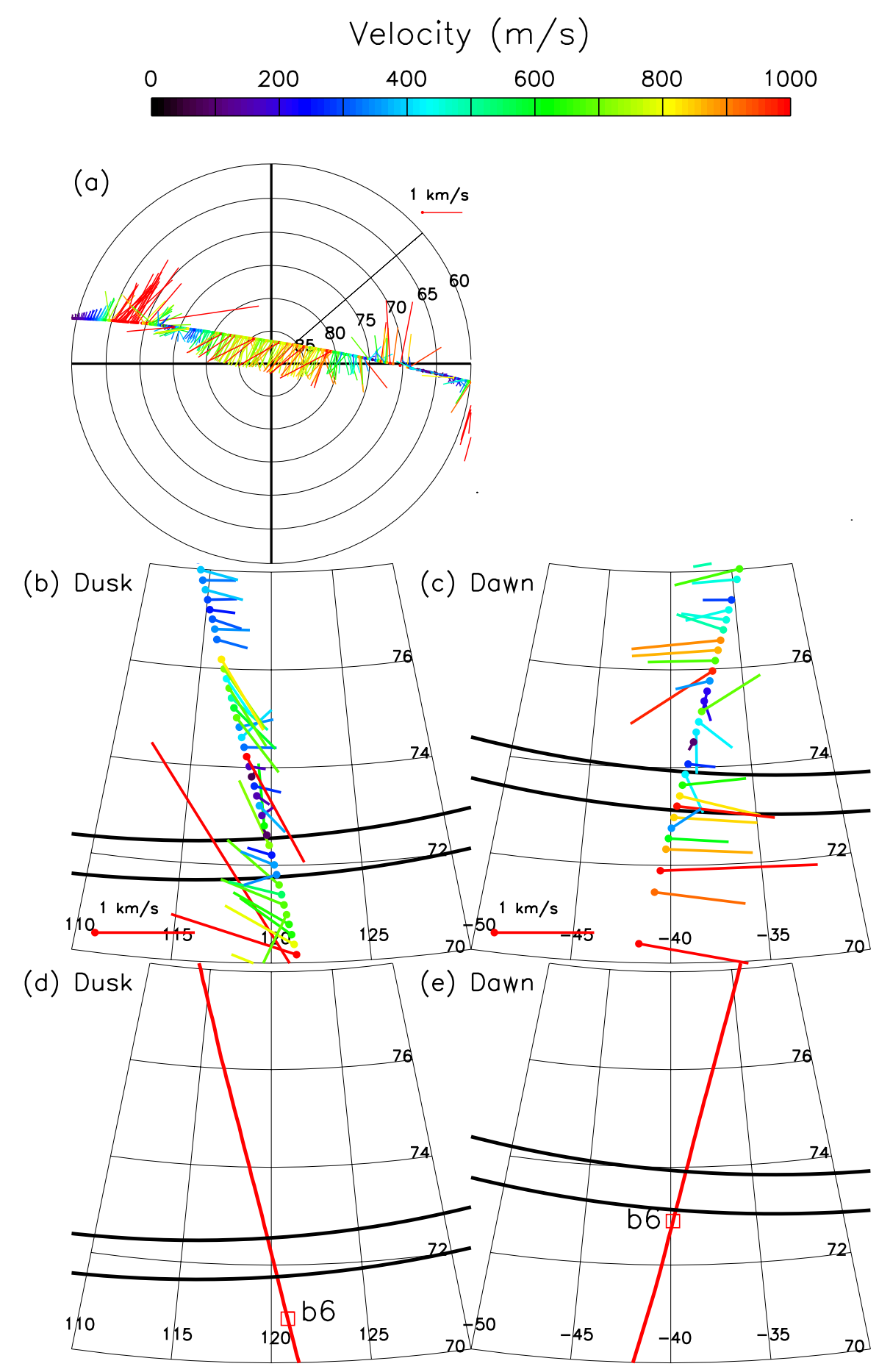

Fig. 5. Observations of the plasma drift by DMSP F13 satellite (at $845 \mathrm{~km}$ altitude) around 13:30 UT. The cross-track and ram direction data have been combined to produce a vector. Panel (a) shows all the data from the transit of the northern polar cap. Panels (b) and (c) show sections of the afternoon and morning plasma flows respectively. The bold lines show the polar cap boundary used in our measurements. The b6 particle precipitation boundary (see text) is marked in panels (d) and (e) with a red square.

spectral width (blue/black)) and ionospheric scatter seen at higher latitudes $\left(\geq 70^{\circ} \mathrm{N}\right)$. The high-latitude scatter shows characteristics consistent with a $B_{z}$ southward period: large poleward velocities (red/yellow) with large Doppler spectral widths (red/green) characteristic of the cusp scatter. This scatter migrates steadily equatorward through the study period. This allows us to determine the location of the PCB in this time sector and also its temporal variation. At 13:00 UT (09:43 MLT), the SWB is at $\sim 74^{\circ} \mathrm{N}$. The FAST and DMSP F14 satellites passed $2 \mathrm{~h}$ to the east $(\sim 11: 45$ MLT) of the 
Goose Bay radar field-of-view at 13:02 and 12:54 UT, respectively. From the particle precipitation characteristics (not shown) observed by both spacecraft, the equatorward boundary of the cusp particle precipitation is located at $74^{\circ} \mathrm{N}$ latitude, providing independent verification of the PCB derived from the Goose Bay data (although at a later local time). At 13:30 UT, the SWB was located at $\sim 73^{\circ} \mathrm{N}$ and then migrated steadily equatorward to $70^{\circ} \mathrm{N}$ latitude at 14:00 UT, an equatorward motion of $185 \mathrm{~ms}^{-1}$. This equatorward migration is consistent with the prevailing IMF $B_{z}$ southward conditions. Phan et al. (2001), using SWB data from the Halley, Antarctica, SuperDARN radar (conjugate to the Goose Bay radar), had estimated the polar cap equatorward expansion to be at the rate of $150 \mathrm{~ms}^{-1}$. The Halley radar data had no low spectral width data (i.e. all the scatter showed spectral widths consistent with cusp scatter) so the determination of the SWB from its data must be considered to be less accurate. The southern SWB was typically one degree poleward of the northern SWB, consistent with the prevailing dipole tilt conditions at the time which would cause the summer (southern) cusp to be at higher latitudes (Newell and Meng, 1989).

Rodger and Pinnock (1997) noted that the equatorward edge of the cusp particle precipitation is offset from the PCB due to the time of flight of the cusp ions and the poleward convection of the flux tubes containing the precipitating particles. Any phenomena (e.g. cusp $630 \mathrm{~nm}$ auroral emissions or radar Doppler spectral width boundary) related to the cusp precipitation will also be offset from the true location of the PCB. Pinnock and Rodger (2001) illustrated the self-consistency of this approach, deriving typical cusp ion travel times from SWB and convection data available from the SuperDARN radars.

An average offset between the location of the SWB and the true location of the PCB has been derived by the following method. The field-aligned distance traveled by the precipitating ions, from the equatorial magnetopause reconnection X-line to the ionosphere, was calculated from the Tsyganenko 1996 magnetospheric field model (Tsyganenko, 1995, 1996; Tsyganenko and Stern, 1996, hereafter referred to as T96) and is $14.9 R_{E}$. The particle travel time is assumed to be characteristic of that for $3 \mathrm{keV}$ protons at $0^{\circ}$ pitch angle, typical of those found at the equatorward edge of the cusp (Newell and Meng, 1991). These will have a time of flight from the magnetopause reconnection site to the ionosphere of $125 \mathrm{~s}$. The mean of the poleward convection measured directly by the Goose Bay radar line-of-sight velocities on beam 4, at the latitude of the SWB between 13:30 UT and 14:00 UT, was calculated to be $330 \mathrm{~m} / \mathrm{s}$, (standard deviation of $89 \mathrm{~m} / \mathrm{s}$ ). To this we add the velocity of the SWB, $185 \mathrm{~m} / \mathrm{s}$ (the boundary is moving equatorward at the same time as the flux tube is convecting polewards) to arrive at an effective poleward velocity component of $515 \mathrm{~m} / \mathrm{s}$. From these values we find that the polar cap boundary needs to be offset by $0.58^{\circ}$ equatorward from the SWB location. Thus, at 13:30 UT, the PCB is located at $72.4^{\circ} \mathrm{N}$ at 10:14 MLT; at 14:00 UT it is at $69.4^{\circ} \mathrm{N}$ latitude at 10:44 MLT.

This estimate of the dayside polar cap boundary location at $\sim 10: 30$ MLT is supplemented by the PCB determined by examining data taken in the dawn and dusk sectors by the DMSP F13 pass between 13:24 and 13:37 UT. Figure 5 shows a summary of the plasma drift data, panel (5a), and expanded views of the drift data in the dusk and dawn sectors, panels (5b) and (5c). The particle boundary "b6", derived using the classification scheme of Newell et al. (1996) is shown by the red squares in panels $(5 \mathrm{~d})$ and $(5 \mathrm{e})$. This boundary is the poleward limit of sub-visual auroral drizzle, which, in both the dawn and dusk sectors of this pass, is within 0.1 to $0.2^{\circ}$ of latitude of the onset of polar rain precipitation. We have also examined the individual ion and electron spectrograms to verify this identification. In the dawn sector the particle boundary b6 agrees to within $0.4^{\circ}$ of latitude with the location of the convection reversal boundary (CRB), determined as the latitude at which persistent sunward flow was established. Taking the CRB as defining the $\mathrm{PCB}$, this locates it at 73.6 N/06:16 MLT at 13:38 UT. In the dusk sector there is a greater discrepancy between the CRB $\left(72.2^{\circ} \mathrm{N} / 16: 29 \mathrm{MLT}\right.$ at 13:26 UT) and the particle boundary b6 $\left(71.0^{\circ} \mathrm{N}\right)$. We note that the region poleward of b6 and up to $72.2^{\circ}$ latitude is all on sunward convecting plasma. We have decided to use the CRB as the best estimate of the PCB in the dusk sector. The CRB latitudes have been linearly interpolated in time to give their latitude at 13:30 UT, assuming the polar cap boundary expansion was at the rate of $185 \mathrm{~m} / \mathrm{s}$ equatorward derived from the radar data. After fitting a circle to the three PCB locations described above, Fig. 6 shows the boundary location as a function of MLT (solid line) at 13:30 UT and 14:00 UT.

We can use the encounters with the magnetopause by the Equator-S and Geotail satellites in this period, as reported by Phan et al. (2000), as a means of checking the ionospheric estimate of the boundary location. The satellite data allow us to set some limitations on the location of the magnetopause. The T96 model is then used to locate the magnetopause footprint in the ionosphere. This is a coarse check: there is a large degree of uncertainty in locating the moving magnetopause with respect to the spacecraft and also the uncertainty associated with the field line mapping.

Phan et al. (2000, their Fig. 2 and text) suggest that at 13:30 UT the two spacecraft make occasional encounters with the magnetopause, but that the Geotail spacecraft is inside the magnetosphere while Equator-S is predominantly in the magnetosheath. Thus, the magnetopause passed between the two spacecraft (which are separated by $\sim 3 R_{E}$ in the $X$ GSM plane, on the dawn side of the magnetopause). Using this fact, the solar wind dynamic pressure $\left(P_{s w}\right)$ input to the T96 model has been adjusted until the location of the magnetopause passed between the two spacecraft. It was found that at 13:30 UT, the $P_{s w}$ had to be set to $4 \mathrm{nPa}$ (in contrast to the $P_{s w}$ measured by Wind of $1.7 \mathrm{nPa}$ ) to achieve this. (A suitable fit to the satellite data could be obtained over a range of solar wind pressures between $3.2 \mathrm{nPa}$ and $4.7 \mathrm{nPa}$.) The location of the magnetopause was then mapped into the ionosphere by field-line tracing, to give an estimate of the location of the PCB. This exercise has been repeated for 14:00 UT. 


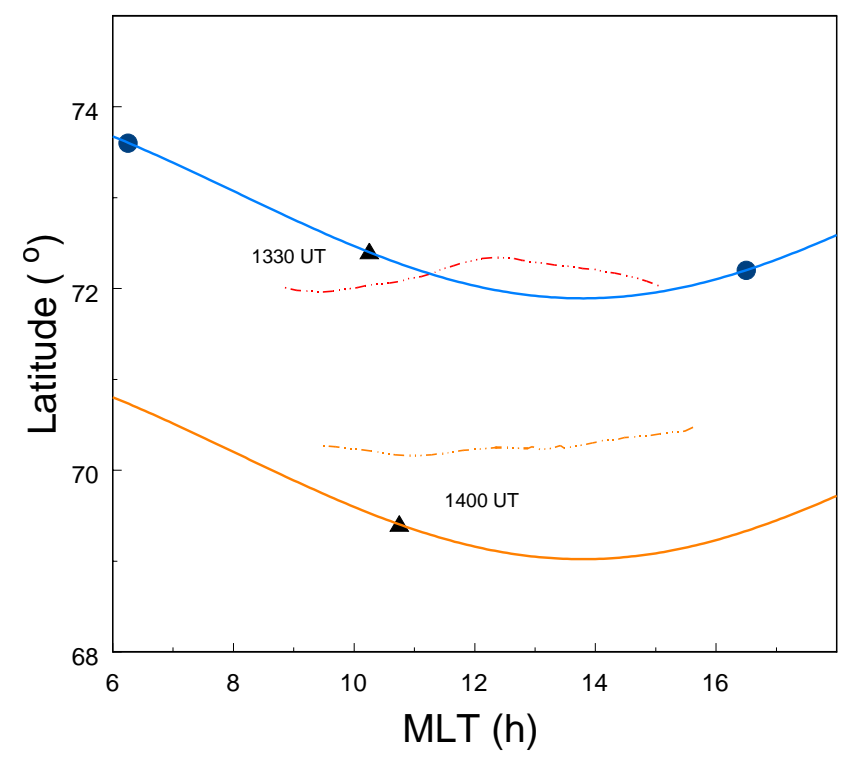

Fig. 6. The location of the polar cap boundary at 13:30 UT (upper curve, solid line), estimated from the Goose Bay radar data (triangle symbol) and the convection reversal boundary derived from DMSP F13 plasma drift data (two circles). The latitude of the boundary ( $y$ axis) is plotted as a function of magnetic local time ( $x$-axis). The lower curve (solid line) shows the location of the PCB at 14:00 UT, determined from the polar cap expansion rate given by the Goose Bay radar data. The triangle symbol represents the location of the polar cap boundary derived from the Goose Bay radar data at 14:00 UT. The two dash-dot lines represent the location of the PCB derived from the estimated magnetopause location (using Equator-S and Geotail satellite data) when mapped to the ionosphere using the Tsyganenko 1996 magnetospheric field model. The high-latitude line represents the boundary at 13:30 UT, the lower latitude line the boundary at 14:00 UT.

At that time both spacecraft are in the magnetosheath and Equator-S makes no magnetopause encounters whilst Geotail is still making frequent encounters, suggesting that it is just outside the magnetopause. In this case the $P_{s w}$ had to be set to $5 \mathrm{nPa}$ to match the spacecraft data with the T96 model magnetopause.

Having to use larger $P_{s w}$ values than actually measured, in order to fit the satellite data, is not surprising. The T96 model has an ellipsoid magnetopause whose parameters are controlled solely by the dynamic pressure. It is well established that the IMF $B_{z}$ component also controls the location of the magnetopause (Roelof and Sibeck, 1993). It has also become clear (Shue et al., 2001) that the IMF history influences the location of the magnetopause. The IMF had been southward for $1.5 \mathrm{~h}$ prior to our observations and hence, magnetopause erosion will have been ongoing, displacing the magnetopause earthward from that predicted solely by the solar wind pressure term. Our findings are pertinent to papers attempting conjugate observations between magnetopause spacecraft and the ionosphere, for example, Neudegg et al. (1999). In particular, in the dawn sector the variation of the solar wind pressure between the measured value at
Wind $(1.7 \mathrm{nPa})$ and the values we have used above make a considerable difference to the local time sector of the ionospheric footprint of the Equator-S satellite (07:30 MLT cf. 09:15 MLT).

The results of this mapping are shown in Fig. 6 as dash-dot lines, with the high-latitude curve representing for 13:30 UT. This curve agrees with the PCB estimate derived from ionospheric data to within $0.6^{\circ}$ and, given the limitations of locating the moving magnetopause, provides confidence in our ionospheric data. The mapping also confirms the equatorward expansion of the PCB, although the curve for 14:00 UT is $0.8^{\circ}$ higher in latitude (at 10:44 MLT) than that derived from the Goose Bay radar data. The 14:00 UT mapping curve represents an upper limit for the PCB location, as by this time, both spacecraft are in the magnetosheath and there is, therefore, a higher degree of uncertainty in locating the magnetopause.

The location of the polar cap boundary for each $2 \mathrm{~min}$ radar scan period is determined by moving the polar cap boundary determined at 13:30 UT (solid, upper curve in Fig. 6) equatorward at a rate of $185 \mathrm{~m} / \mathrm{s}$ for the time elapsed since 13:30 UT. The location of the SWB by the radar has an error of \pm one range gate $(45 \mathrm{~km}$; see André et al., 1997; Pinnock et al., 1999, p. 445) and we have taken this as the uncertainty in our polar cap boundary location.

\subsection{Measuring the reconnection electric field}

As stated by de la Beaujardière et al. (1991), the rate at which flux is added to the polar cap and its equivalence to the reconnection electric field $\left(E_{\mathrm{rec}}\right)$ for a particular segment $(d l)$ of the PCB is represented by:

$\frac{d F}{d t}=\boldsymbol{B} \times \boldsymbol{v}^{\prime} \cdot d l=E_{\mathrm{rec}} \cdot d l$,

where $\frac{d F}{d t}$ is the flux transfer rate, $\boldsymbol{B}$ is the local magnetic field and $\boldsymbol{v}^{\prime}$ is the horizontal velocity of the plasma in the rest frame of the separatrix. Equation (1) in our analysis thus becomes:

$\frac{d F}{d t}=E_{\mathrm{rec}} \cdot d l=B_{z}(v \cdot \cos \theta-u) d l$,

where $v$ is the plasma velocity in the Earth's frame, $B_{z}$ is the vertical component of the AACGM model field (at 300 $\mathrm{km}), \theta$ is the angle between the plasma flow direction and the normal to the PCB and $u$ is the velocity of the PCB, also in the normal direction. The value of $\boldsymbol{v}^{\prime}$ is derived in the following fashion:

1. At any particular longitude the true vector within the PCB uncertainty limits is identified;

2. The orientation of the PCB (its angle relative to a line of geomagnetic latitude) at this longitude is determined from the PCB data points on either side of the longitude; 
3. The flow orthogonal to the PCB is determined, $v \cdot \cos \theta$;

4. The speed of the PCB $(u)$, in the direction orthogonal to the orientation of the PCB, over the preceding twominute interval is determined;

5. The flow across the PCB is combined with the velocity of the PCB to give $v^{\prime}=v \cdot \cos \theta-u$. Thus, equatorward motion of the separatrix will enhance the flow across it, poleward motion will reduce the flow across it.

The reconnection electric field, $E_{\mathrm{rec}}$, is then derived from assuming:

$E_{\mathrm{rec}}=-v^{\prime} \times B_{z}$.

This $E_{\text {rec }}$ value applies over the longitude range, $d l$, defined by the distance between the midpoints to the neighboring longitudes at the separatrix that have a true vector, in both directions. Where true vectors are continuous in coverage (e.g. Fig. 3a, 14:00 MLT to $\sim 16: 00$ MLT) this will be approximately $50 \mathrm{~km}$ on either side of a vector (the radar beam width being approximately $100 \mathrm{~km}$ at this latitude). Note that where gaps exist in the radar backscatter coverage (e.g. Fig. 3a. $\sim 10: 30$ MLT to $\sim 12: 00$ MLT), the value of $E_{\text {rec }}$ can apply for a much greater distance (i.e. a larger $d l$ ).

By summing all the values along the dayside merging line, the total potential difference along the line, $\Phi_{\mathrm{rec}}=\sum_{i} E_{r e c_{i}}$. $d l_{i}$, can be determined.

Note that $E_{\text {rec }} \cdot d l$ has only been calculated between the longitude limits set by where we have radar true vectors. These limits are between approximately 09:00 and 16:00 MLT. The equipotential contours in Fig. 3 suggest that flows across the boundary exist outside these limits. e.g. out to a limit of 17:00 MLT in the afternoon cell, as shown by the DMSP data (Fig. 5b), which shows poleward flow crossing the PCB. The morning cell flow limits are harder to determine because of the lack of data, but using the 13:3813:40 UT equipotential pattern (which has DMSP data defining the morning cell in the 06:00 MLT sector), it may extend to 06:30 MLT. The DMSP data at 06:15 MLT shows no poleward flow crossing the boundary (Fig. 5c), but rather an equatorward flow, which would be consistent with a reconnection site at later local times, causing the boundary to move equatorward in this local time sector (Cowley and Lockwood, 1992).

\subsection{The reconnection electric field}

In Fig. 7 we present a summary of the reconnection electric field measurements derived from applying the above technique to the SuperDARN radar data for the two-minute scans in the period 13:30 UT to 14:00 UT. The top panel shows the values as line plots for sample two-minute scans, plotted against the magnetic local time location of the measurements. Where more than one line from the same scan period exists (e.g. 13:40 UT scan in the 16:00 MLT sector), this is where data from more than one radar exists at a given location; it is thus possible to produce a vector from each radar data set. The middle panel shows the $E_{\text {rec }}$ values derived in the whole interval, with median and quartile values shown. The panels show that the distribution of the reconnection electric field across the dayside merging line is remarkably steady over the $30 \mathrm{~min}$, except in the 15:00-16:00 MLT sector, where the spread between the upper and lower quartile reaches $18 \mathrm{mV} / \mathrm{m}$. The mean reconnection electric field (all data points (Fig. 7b) in the interval 13:30-14:00 UT) is $22.0 \mathrm{mV} / \mathrm{m}$.

The third panel (Fig. 7c), plotted against Universal Time, shows the variation of the dayside reconnection potential, $\Phi_{\text {rec }}$, determined from the radar true vectors (solid line). The extent to which the radar's true vectors provide coverage across the whole dayside merging line will determine how close this value is to the total potential associated with dayside reconnection. The radar true vectors exist over a time sector spanning $7 \mathrm{~h}$ of MLT; the equipotential pattern shows this may be extended to $10.5 \mathrm{~h}$ of MLT, e.g. in Fig. $3 \mathrm{~b}$ flow is crossing the boundary between 17:00 and 06:30 MLT. So it is possible that the radar's true vectors can only provide the reconnection electric field over $\sim 67 \%$ of the merging line. The total potential measured by the radars varied between 75.07 and $107.3 \mathrm{kV}$, with a mean value of $89.3 \mathrm{kV}$. Also shown in Fig. $7 \mathrm{c}$ is the total cross polar cap potential (dashed line) determined from the fitted global equipotential pattern. This varied between 63 and $85 \mathrm{kV}$ with a mean value of $69 \mathrm{kV}$. This can be compared with the value of $95 \mathrm{kV}$ given by integrating along the path of the DMSP F13 satellite for the interval 13:24 to 13:40 UT. The equipotential maps in Fig. 3 suggest that the satellite passed very close to the centers of the morning and afternoon convection cells and hence, provided a good estimate of the total cross polar cap potential. The value of the total cross polar cap potential is examined further in the discussion section.

\subsubsection{Errors and uncertainties}

Flow vectors used to determine flow across the polar cap boundary are subject to the errors of the radar line-of-sight velocity $\left(V_{\mathrm{los}}\right)$ measurements; data with errors greater than $200 \mathrm{~m} / \mathrm{s}$ are excluded from the convection mapping process. The velocity component transverse to the radar beam, determined from the global equipotential pattern, has an element of uncertainty associated with it that cannot be readily expressed as an error measurement. This particular period has been subject to intense study, in terms of the quality of the fitted convection pattern, and is described in Chisham and Pinnock (2002). The reader is referred to that paper for detailed discussion.

We have used a smooth, circular polar cap boundary. An estimate of the likely maximum error arising from incorrectly determining the orientation of the PCB was given in Sect. 2.3 as being $<20 \%$. Small-scale motion of the boundary, both in the spatial and temporal sense, does exist (e.g. Sandholt et al., 1998). However, this motion occurs on a size comparable to the errors $( \pm 45 \mathrm{~km})$ in locating the spectral width boundary in the radar data set. Pinnock et al. (1999) performed 

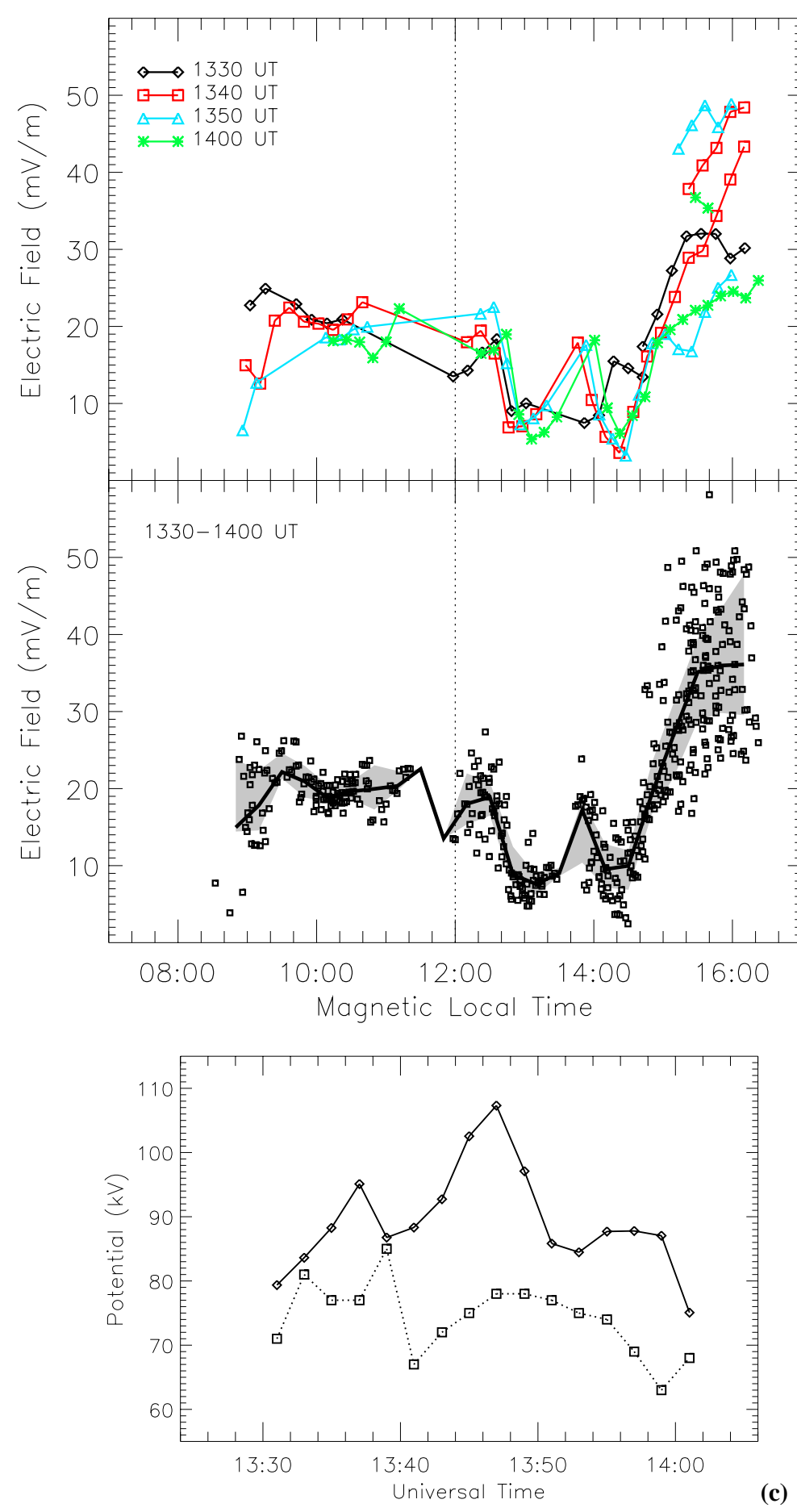

(a), (b)

(c)

Fig. 7. Panel (a): The reconnection electric field ( $y$-axis) measured at a range of MLTs ( $x$-axis) for 4 radar scan periods. Panel (b): all the reconnection electric field values measured from 13:30-14:00 UT. The solid line is the median reconnection electric field for a given MLT, the shading marks the upper and lower quartiles. Panel (c): the total reconnection potential ( $y$-axis) measured across the dayside merging line sampled by the radar coverage ( $\sim 7 \mathrm{~h}$ of MLT, see text for discussion) over the UT period ( $x$-axis) of the study is shown by the solid line. The total crosspolar cap potential, as determined by the convection mapping process, is shown by the dotted line.

a detailed study of the boundary motion, using the spectral width data from radars, and confirmed that boundary motions (within one scan period, 100 s) seldom exceeded the errors in the measurement. They used a highly smoothed bound- ary in computing the reconnection electric field and noted that they still had measurements which accounted for close to $100 \%$ of the total cross polar cap potential measured by DMSP satellite, suggesting that no significant potential was 


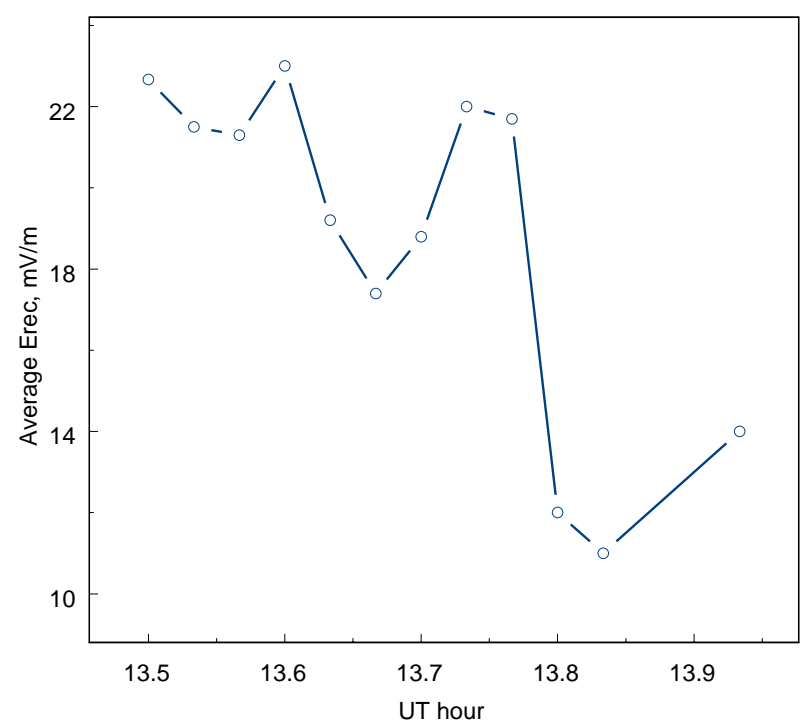

Fig. 8. The average reconnection electric field $\left(E_{\mathrm{rec}}\right)$ in the magnetic longitude sector $\left(0-15^{\circ}\right)$ conjugate to the Equator-S satellite as a function of universal time.

being omitted. We conclude that, while small-scale detail in the reconnection electric field may be missed, the value of the reconnection electric field over a period of several minutes is accurately quantified.

An estimate of the uncertainties involved can also be gained from polar cap boundary locations where data from more than one radar are available. This provides a "true vector" from each radar and hence, more than one estimate of the reconnection electric field. This is shown in Fig. 7 by pairs of lines (same colour) in certain MLT sectors. From this it can be seen that while multiple radar measurements can agree to within $\sim 5 \mathrm{mV} / \mathrm{m}$ (e.g. 13:40 UT (red line) in Fig. 7a in the 15:00-16:00 MLT sector), disagreements can be in excess of $20 \mathrm{mV} / \mathrm{m}$ for measurements from one epoch (13:50 UT, blue line in Fig. 7a) in the 15:00-16:00 MLT sector. Careful inspection of these extreme examples shows that the radar (Iceland East) giving the low values has a zonal viewing direction, and the high values of $E_{\text {rec }}$ come from a meridional pointing radar (Finland). As the latter has beams that are orthogonal to the PCB, their line-of-sight measurements (i.e. the raw data input to the convection modeling) are a direct measurement of the flow across the boundary. Inspection of these line-of-sight values in the vicinity of the boundary confirms that the high $E_{\text {rec }}$ values are representative of the true flow across the boundary. We have left the erroneous (lower $E_{\text {rec }}$ ) values in the plots to illustrate the errors that may arise when only zonal pointing radars are contributing data.

\subsection{Mapping to the magnetopause}

In order to relate the ionospheric measurements to reconnection at the magnetopause, and the magnetopause observations by the Geotail and Equator-S satellites (Phan et al., 2000), we have used the T96 model to perform field line mapping in a manner identical to that described in Coleman et al. (2000).

The field line mapping has been done for 13:30 UT using the adjusted solar wind pressure value $(4 \mathrm{nPa})$ as described in Sect. 2.3. The results of the mapping are shown in Fig. 3 (upper panel). The Geotail spacecraft (triangle symbol in Fig. 3) mapped to 08:00 MLT (and just equatorward of the PCB) while Equator-S was positioned at 10:30 MLT (and just poleward of the $\mathrm{PCB}$ ).

The limits of the dayside merging line, taken as between 17:00 and 06:30 MLT and at the latitudes given by our polar cap boundary estimate, have been mapped out to the magnetopause and the points at which they cross the $Z=0$ (equatorial) plane have been determined. The duskward limit of the merging line maps to $X=-0.3 R_{E}, Y=12.6 R_{E}$ GSM; the dawnward limit to $X=-9.0, Y=-15.5 R_{E}$ GSM. This means that the dayside reconnection $X$-line spans $38.2 R_{E}$ (in the $Z=0$ plane) on the magnetopause surface of the T96 model. This result is very insensitive to the solar wind pressure value used; using the range of solar wind pressures (3.2 to $4.7 \mathrm{nPa}$ ) given in Sect. 2.3 varies the $\mathrm{X}$-line length by only $0.2 R_{E}$.

\subsection{Satellite observations at the magnetopause}

The Geotail satellite maps to a region where no ionospheric data is available (see Fig. 3, 07:40 MLT sector) but the Equator-S satellite maps into the Goose Bay and Stokkseyri (Iceland West) radars' field-of-view, in the 09:00-10:00 MLT sector. Phan et al. (2000, their Fig. 2c), identified 3 plasma jets in the Equator-S data in the interval 13:30-14:00 UT, at 13:34, 13:40 and 13:45 UT.

From Fig. $7 \mathrm{~b}$ it can be seen that the ionospheric reconnection electric field is always above $0 \mathrm{mV} / \mathrm{m}$ in this sector. In Fig. 8 the average $E_{\text {rec }}$ value in the longitude sector between 0 and $15^{\circ}$ east magnetic longitude (08:45-09:45 MLT at 13:30 UT, the region closest to 10:30 MLT which has contiguous radar data) is plotted from 13:30-14:00 UT. $E_{\text {rec }}$ varies considerably through the period, with peak values at 13:30, 13:36, 13:45 UT and 14:00 UT. If one notes that the PCB equatorward motion $(185 \mathrm{~m} / \mathrm{s})$ is contributing nearly $10 \mathrm{mV} / \mathrm{m}$ to $E_{\text {rec }}$, then from this base line level one can see that the plasma is accelerated across the PCB in a series of surges.

\section{Discussion}

\subsection{The longitudinal extent of the magnetopause reconnec-} tion X-line

The SuperDARN radar data sets a lower limit of $7 \mathrm{~h}$ for the width of the dayside merging line. The equipotential patterns derived from the radar and DMSP F13 data show flow crossing the polar cap boundary from $\sim 06: 30$ MLT to $\sim$ 17:00 MLT, or 10.5 h of MLT.

It is possible to check for consistency within our data by noting that the polar cap boundary, in the noon sector, was 
observed to move equatorward at the rate of $3^{\circ}$ in $30 \mathrm{~min}$ (Fig. 4). Taking this expansion rate, and assuming a circular polar cap boundary, this equates to a flux transfer rate of $1.159 \times 10^{5} \mathrm{~T} / \mathrm{s}$ or, using Eq. (1), this equates to a mean potential of $\sim 116 \mathrm{kV}$. Taking this value, and the mean reconnection electric field measured by the radars $(22.0 \mathrm{mV} / \mathrm{m}$ derived from the data shown in Fig. 7b), implies a dayside merging line of $5100 \mathrm{~km}$. At a mean latitude of $72^{\circ}$, this translates to a merging line that spans $\sim 10 \mathrm{~h}$ of MLT, in close agreement with the equipotential patterns.

We conclude that the dayside merging line on this day spanned $\sim 10 \mathrm{~h}$ of MLT, which magnetic field line mapping showed gave a magnetopause reconnection X-line of $38 R_{E}$ (Sect. 2.6). This gives an average reconnection electric field of $\sim 0.5 \mathrm{mV} / \mathrm{m}$ at the magnetopause. This is comparable to the average reconnection electric field produced from many satellite passes in the noon sector of the magnetopause (e.g. Lindqvist and Mozer, 1990).

A dayside merging line of $10 \mathrm{~h}$ MLT is very large compared to theoretical studies which have predicted a typical dayside merging line of $\sim 4 \mathrm{~h}$ of MLT for a cross-polar cap potential of $100 \mathrm{kV}$ (e.g. Crooker and Toffoletto, 1995). Recent modeling work by Coleman et al. (2000) found that the dayside merging line predicted by the anti-parallel merging hypothesis varied with dipole tile angle; it ranged between $3 \mathrm{~h}$ (summer) and $8 \mathrm{~h}$ (winter) of MLT. Previous experimental data have suggested values between $3 \mathrm{~h}$ (Pinnock and Rodger, 2001) and greater than $8 \mathrm{~h}$ of MLT (Crooker et al., 1991) for the dayside merging line in the ionosphere.

Observations of the length of the magnetopause $\mathrm{X}$-line are extremely difficult to make. Lewis et al. (1998) and Yeoman et al. (1999) used an indirect observational technique (expansion of the polar cap boundary combined with use of a reconnection model) to infer magnetopause X-lines of dimension 12 and $27 R_{E}$, respectively. Original estimates of the longitudinal extent of FTEs on the magnetopause were of the order of $1 R_{E}$ (Russell and Elphic, 1979), but subsequently workers suggested a greater extent (e.g. Southwood et al., 1988). Lockwood and Davis (1996) argued for a magnetopause X-line length of at least $3 \mathrm{~h}$ of MLT based on interpretation of longitudinal passes of DMSP satellites through the cusp ionosphere.

Statistical or synthesized convection patterns for southward IMF (e.g. Heppner and Maynard, 1987; Weimer, 1995; Ruohoniemi and Greenwald, 1996) do show flow rotating poleward and flowing anti-sunward over $8 \frac{1}{2}$ to $11 \mathrm{~h}$ of MLT on the dayside, in closer agreement with our findings. We also note that Shepherd et al. (2000) suggested that if the reconnection X-line were to span the whole dayside magnetopause, as reported here, it could explain observations of the simultaneous response in ionospheric flows over a large range of MLTs following a southward turning of the IMF (e.g. Ridley et al., 1998). Our findings also support Lockwood (1997) and Provan and Yeoman (1999), who considered cusp particle precipitation observations and plasma flow data and concluded that the ionospheric projection of the magnetopause $\mathrm{X}$-line was wider than that predicted solely by cusp particle precipitation data (Newell and Meng, 1992).

From the the discussion above, it is clear that the observation reported here is at the extreme of previous measurements and assumptions. For a purely southward IMF both the component merging and the anti-parallel merging models predict a reconnection X-line of maximum extent. Nishida and Maesawa (1971) have pointed out that for component merging the length of the magnetopause $\mathrm{X}$-line scales as roughly $\sin (\Theta / 2)$, where $\Theta$ is the angle between the magnetosheath and magnetospheric field lines $\left(\Theta=180^{\circ}\right.$ being the antiparallel condition).

\subsection{Longitudinal variation in reconnection rate}

The distribution of the reconnection electric field, along the dayside merging line, retains stable characteristics throughout a 30-min study period. In a coarse sense, there is a gradient along the merging line, with larger $E_{\text {rec }}$ values observed at the eastern (afternoon) end. We do not have an explanation for this gradient. The reduction in $E_{\text {rec }}$ in the 14:00 MLT sector, to values below $10 \mathrm{mV} / \mathrm{m}$, is an interesting feature. Note also that the variance in our measured reconnection rate is not great in this local time sector. The convection pattern (see Fig. 3) in the 14:00 MLT sector has equipotentials that are almost parallel to the modeled polar cap boundary, giving sunward (return) flow and thus accounting for the low $E_{\text {rec }}$ values. One possible explanation is that the assumption of a circular polar cap boundary is in error in this sector and, therefore, the flow is not parallel to it. Just immediately poleward of the modeled PCB, the equipotentials show significant poleward flow. We also note that this region (sunward, return flow in the 14:00 MLT sector) is co-located with the 14:00 MLT "hot spot" in auroral activity (see Moen et al., 1994 and references therein). Auroral data show discrete east-west arcs and also spiral formation, and have been interpreted as revealing fine scale structure in the region 1 currents in this sector. The flow pattern (Fig. 3) may represent modification of the electric field imposed on the ionosphere due to conductivity variations associated with this auroral feature, or direct modification of the imposed electric field by the processes responsible for the auroral activity. Causative mechanisms involving Kelvin-Helmholtz instabilities acting on the low latitude boundary layer (LLBL) or perturbations in the magnetopause pressure balance have been proposed. Greater scatter is observed in the $E_{\text {rec }}$ values in the late afternoon sector, but this is mainly due to the values contributed by zonal pointing radars identified in Sect. 2.5.1 and is not indicating more variability in the reconnection rate in this sector.

3.3 Potential associated with dayside reconnection and the total cross polar cap potential

By considering the reference frame in which measurements are made, together with some of the limitations of the techniques used, it is possible to show that a good level of agree- 
ment exists between the values derived for the total cross polar cap potential (from the equipotential maps), the total potential measured along the path of the DMSP F13 satellite and the dayside merging line potential derived from the radar flow vector measurements.

We consider in detail the convection map produced at 13:38-13:40 UT (Fig. 3b). The total cross polar cap potential derived from the equipotential contours (derived from a combination of the radar data, satellite plasma drift data and the statistical convection model) is $84 \mathrm{kV}$ (Fig. 7c).

This evaluation $(84 \mathrm{kV})$ can be compared with the DMSP F13 measurement of potential along a path that took it close to the foci of the convection cells. The two techniques are not completely independent, as the satellite plasma drift data are used in both. According to the equipotential patterns the satellite would have passed just to the west of the maximum potential associated with the afternoon cell, so if anything it should have measured a slightly lower value. In actuality, it measured $95 \mathrm{kV}, 11 \mathrm{kV}$ higher. The DMSP measurement is of course taken over a period of $\sim 14 \mathrm{~min}$, so some difference may be expected between the two techniques. Also, it is commonly found that there is usually an offset to the potential at the end of each polar pass (ideally it should be zero). A linear correction to the entire potential curve is done to force the end point to go to zero potential (Hairston et al., 1998). This implies some uncertainty in the DMSP calculation arising from temporal variations in the ion drifts during the $\sim 14$ min pass. An additional factor is that plasma drift measurements by polar orbiting satellites show considerable structure on a variety of scale sizes in the auroral and polar cap regions. The median filtering technique applied to the radar line-of-sight measurements in the mapping process has the effect of removing these extremes so one might expect a lower overall potential. This may account for some of the $11 \mathrm{kV}$ potential difference between the two techniques.

Neither of these measurements is made in the frame of the moving polar cap boundary. To compare with measurements made in that reference frame, we must add the contribution made by the polar cap expansion. The characteristics of the radar backscatter from the Goose Bay radar showed the polar cap boundary expanding equatorward (steadily, over a 30min period) at the rate of $185 \mathrm{~m} / \mathrm{s}$, equivalent to an electric field value of $9.24 \mathrm{mV} / \mathrm{m}$. If we take this value and apply it across the $11 \mathrm{~h}$ of MLT over which the potential is measured by DMSP (17:00 to 06:00 MLT), at a latitude of $72^{\circ}$, we have a total potential associated with the polar cap boundary motion of $60 \mathrm{kV}$. This gives a total potential of $95 \mathrm{kV}+60 \mathrm{kV}$ $=155 \mathrm{kV}$.

The dayside reconnection electric field derived from the SuperDARN radar data gives a total potential of $105 \mathrm{kV}$ at 13:38 UT (Fig. 7c), this being measured in the rest frame of the polar cap boundary. This measurement was made over $7 \mathrm{~h}$ of MLT, less than the width of the dayside merging line. Extrapolating the measurement from $7 \mathrm{~h}$ to $10 \mathrm{~h}$ (i.e. $105 \mathrm{kV} \times$ $10 / 7$ ) gives a likely total dayside merging potential of $150 \mathrm{kV}$. This is in good agreement with the estimate derived for the total cross polar cap potential from the DMSP F13 satellite measurement when they are translated to the moving boundary reference frame. It also shows that the dayside reconnection is dominant at this time, being able to account for nearly all the total cross polar cap potential.

Finally, there is a subtle point concerning the convection pattern maps and the use of "true vectors" (see Sect. 2.3 and Chisham et al., 2002). By examining the equipotential contours in Fig. 3b, the potential spanning from 16:00 to 09:00 MLT line along the polar cap boundary is $\sim 49 \mathrm{kV}$. Moving this into the moving boundary reference frame (as above) adds a further $38 \mathrm{kV}$, giving a total potential of $87 \mathrm{kV}$. This compares with the reconnection potential derived from the radar data's "true vectors" along the same polar cap boundary interval of $105 \mathrm{kV}$. The difference between these two figures shows the difference between using vectors derived solely from the fitted equipotential pattern (so-called "fit vectors") and using "true vectors" (vectors derived form the radar line-of-sight velocity and the velocity component transverse to the radar beam given by the fitted equipotential pattern). True vectors can differ substantially (in magnitude and direction) from the fitted equipotential pattern. The close agreement between the DMSP F13 derived potentials and those derived using the "true vectors" confirms that the "true vectors" provide the more accurate measurement of the convection electric field, as found by Chisham et al. (2002). In this case study, by using "true vectors", we give greater emphasis to the line-of-sight velocity measurements. This would have the effect of reducing the impact of the median filtering (i.e. restoring some of the smaller scale detail). In the case of the Goose Bay and Finland radar data, which have beams that are orthogonal to the polar cap boundary, this line-of-sight measurement is also a direct measurement of the flow across the boundary.

Polar orbiting satellites, such as the DMSP F13 satellite, are often used to derive a value for the total cross-polar cap potential. However, the width of the dayside merging line $(10 \mathrm{~h})$ on this day means that a measurement made along the 17:00/06:00 MLT is also a very significant proportion of the dayside reconnection potential. By contrast, Cowley and Lockwood (1992) envisaged the dayside X-line potential contributing to half the total cross polar potential (their Fig. 4). This is because, in their example model, the dayside merging line was of much smaller dimension ( $\sim 3 \mathrm{~h}$ of MLT).

\subsection{Relationship to observations of Phan et al. (2000, 2001).}

The findings in this paper agree with the conclusions of Phan et al. $(2000,2001)$. They deduced that a stable, quasistationary X-line, spanning dawn to dusk and of $\sim 40 R_{E}$ extent, existed and this is confirmed by our observations. However, our data in the ionospheric region approximately conjugate to the Equator-S satellite shows that the reconnection rate varied considerably over a $30-\mathrm{min}$ period, although reconnection was always active. This is consistent with the many previous ionospheric observations of bursty flow in the vicinity of the dayside polar cap boundary (e.g. Lockwood 
et al., 1989; Pinnock et al., 1993, 1995; Provan and Yeoman, 1999) and also with the temporal variability reported from satellite observations of the reconnection electric field (e.g. Lindqvist and Mozer, 1990).

The dawn side limit of the merging line maps to nearly $X=-9 R_{E}(\mathrm{GSM})$, a considerable distance behind the terminator compared to the dusk sector (which maps to $X=$ $\left.-0.3 R_{E}\right)$. This results from the very rapid increase in the negative X-plane direction of the last closed field lines as one moves past the terminator. It also reinforces the findings of Maynard et al. (1995), who, using statistical convection models, found that a significant portion of the dayside reconnection potential resulted from reconnection sites on the flanks of the magnetopause.

\section{Conclusions}

The ability of the SuperDARN radar network and DMSP satellites to make measurements of the extent and rate of dayside reconnection has been illustrated. This study has only reported a limited time period: the period was chosen because of the coincident satellite observations of magnetopause reconnection. Other study periods, spanning several hours of universal time are currently in progress.

The dayside merging line was $\sim 10 \mathrm{~h}$ of MLT wide, giving a magnetopause reconnection X-line of $\sim 38 R_{E}$. This is possibly the greatest extent for a magnetopause reconnection $\mathrm{X}$-line reported in the literature, suggesting that for purely IMF southward conditions, the X-line spans the whole dayside magnetopause. It provides evidence to support the suggestion by Shepherd et al. (2000) that, if the reconnection $\mathrm{X}$-line spanned the whole dayside magnetopause, it would explain the observation of an instantaneous response over a wide range of MLTs following a southward turning of the IMF (e.g. Ridley et al., 1998).

The reconnection electric field was measured by the radars across $7 \mathrm{~h}$ of MLT and shown to be very stable over a 30min period. The average reconnection electric field in the ionosphere was $22.5 \mathrm{mV} / \mathrm{m}$. At the magnetopause this would map to $0.5 \mathrm{mV} / \mathrm{m}$. An intriguing feature was the minimum in reconnection electric field at 14:00 MLT. We have speculated that this may relate to the 14:00 MLT auroral hotspot, the minimum being due either to an actual minimum in $E_{\text {rec }}$ associated with the hotspot or our technique failing to accurately model the polar cap boundary in this sector (also due to the auroral activity).

We have set the observations and deductions made by Phan et al. $(2000,2001)$ in the context of the whole dayside reconnection activity. We have confirmed their deductions about the length of the dayside reconnection X-line. While our results support their statement that the spacecraft observations provided "evidence for a stable and extended reconnection line", we reveal more of the temporal and spatial variations in the reconnection rate. Reconnection was always occurring but the rate varied with time, both when considering the sum total of dayside reconnection and also when considering the ionosphere conjugate to the Equator-S satellite observations.

Acknowledgements. The CUTLASS SuperDARN radars used in this study are supported by the Particle Physics and Astronomy Research Council (PPARC), UK, the Swedish Institute for Space Physics, Uppsala and the Finnish Meteorological Institute, Helsinki. The other SuperDARN radars used in this study are supported by the national funding agencies of the U.S.A., Canada and France. The Wind and IMP-8 data were accessed from the NSSDC CDAWeb database. We are grateful to Drs. R. Lepping and A. Szabo, NASA Goddard Space Flight Center, for making these available and Dr. K. Ogilvie, PI on the Wind SWE instrument. The DMSP particle detectors were designed by Dave Hardy of AFRL, and data obtained from JHU/APL. We thank Dave Hardy, Fred Rich, and Patrick Newell for their use. The DMSP ion drift data for this work were provided through NASA grant NAG5-9297. LANL energetic particle data was provided courtesy of G. D. Reeves. The NOAA satellite data were supplied by Dr. A. Kadokura at WDC C2, NIPR, Japan.

Topical Editor T. Pulkkinen thanks two referees for their help in evaluating this paper.

\section{References}

André, R., Hanuise, C., Villain, J-P., and Cerisier, J-C.: HF-radars; Multifrequency study of the refraction effects and localization of scattering, Radio Sci., 32, 153, 1997.

André, R., Pinnock, M. and Rodger, A. S.: On the SuperDARN autocorrelation function observed in the ionospheric cusp, Geophys. Res. Lett., 26, 3353, 1999.

Baker, K. B. and Wing, S.: A new magnetic coordinate system for conjugate studies at high latitude, J. Geophys. Res., 94, 9139, 1989.

Baker, K. B., Greenwald, R. A., Ruohoniemi, J. M., Dudeney, J. R., Pinnock, M., Newell, P. T., Greenspan, M. E., and Meng, C.I.: Simultaneous HF-radar and DMSP observations of the cusp, Geophys. Res. Lett., 17, 1869, 1990.

Baker, K. B., Dudeney, J. R., Greenwald, R. A., Pinnock, M., Newell, P. T., Rodger, A. S., Mattin, N., and Meng, C.-I.: HF radar signatures of the cusp and low-latitude boundary layer, J. Geophys. Res., 100, 7671, 1995.

Baker, K. B., Rodger, A. S., and Lu, G.: HF-radar observations of the rate of magnetic merging: a GEM boundary layer campaign study, J. Geophys. Res., 102, 9603, 1997.

Blanchard, G. T., Ellington, C. L., Lyons, L. R., and Rich, F. J.: Incoherent scatter radar identification of the dayside magnetic reconnection separatrix and measurement of magnetic reconnection, J. Geophys. Res., 106, 8185, 2001.

Brittnacher, M., Fillingim, M., Parks, G., Germany, G., and Spann, J.: Polar cap area and boundary motion during substorms, J. Geophys. Res., 104, 12 251, 1999.

Chisham, G. and Pinnock, M.: Assessing the contamination of SuperDARN global convection maps by non-F-region backscatter, Ann. Geophysicae, 20, 13, 2002.

Chisham, G., Coleman, I. J., Freeman, M. P., Pinnock, M., and Lester, M.: Ionospheric signatures of split reconnection $\mathrm{X}$-lines during conditions of IMF $B_{z}<0$ and $\left|B_{Y}\right| \approx\left|B_{z}\right|$ : evidence for the anti-parallel merging hypothesis, J. Geophys. Res., 107 (A1O), 1323, doi: 10.1029/20001JA009124, 2002. 
Coleman, I. J., Pinnock, M. and Rodger, A. S.: The ionospheric footprint of anti-parallel merging regions on the dayside magnetopause, Ann. Geophysicae, 18, 511, 2000.

Cowley, S. W. H. and Lockwood, M.: Excitation and decay of solar wind driven flows in the magnetosphere-ionosphere system, Ann. Geophysicae, 10, 103, 1992.

Crooker, N. U., Toffoletto, F. R., and Gussenhoven, M. S.: Opening the cusp, J. Geophys. Res., 96, 3497, 1991.

Crooker, N. U. and Toffoletto, F. R.: Global aspects of Magnetopause-Ionosphere coupling: review and synthesis, Physics of the Magnetopause, Geophysical Monograph 90, published by the American Geophysical Union, 363-370, 1995.

de la Beaujardière, O., Lyons, L. R., and Friis-Christensen, E.: Sondrestrom radar measurements of the reconnection electric field, J. Geophys. Res., 96, 13 907, 1991.

Feldstein, Y. I.: On morphology of auroral and magnetic disturbances at high latitudes, Geomag. Aeron., 3, 183, 1963.

Frank, L. A. and Craven, J. D.: Imaging results from Dynamics Explorer-1, Rev. of Geophys., 26, 249, 1988.

Freeman, M. P. and Southwood, D. J.: The effect of magnetospheric erosion on mid-latitude and high-latitude ionospheric flows, Planet. Space Sci., 36, 509, 1988.

Greenwald, R. A., Baker, K. B., Dudeney, J. R., Pinnock, M., Jones, T. B., Thomas, E. C., Villain, J.-P., Cerisier, J.-C., Senior, C., Hanuise, C., Hunsucker, R. D., Sofko, G., Koehler, J., Nielsen, E., Pellinen, R., Walker, A. D. M., Sato, N., and Yamagishi, H.: DARN/SuperDARN: A global view of the dynamics of highlatitude convection, Space Sci. Rev., 71, 761, 1995.

Hairston, M. R., Heelis, R. A., and Rich, F. J.: Analysis of the ionospheric cross polar cap potential drop using DMSP data during the National Space Weather Program study period, J. Geophys. Res., 103, 26337-26347, 1998.

Heppner, J. P. and Maynard, N. C.: Empirical high-latitude electric field models, J. Geophys. Res., 92, 4467, 1987.

Holzworth, R. H. and Meng, C.-I.: Mathematical representation of the auroral oval, Geophys. Res. Lett., 2, 377, 1975.

Hones, E. W., Craven, J. D., Frank, L. A., Evans, D. S., and Newell, P. T.: The horse-collar aurora - a frequent pattern of the aurora in quiet times, Geophys. Res. Lett., 16, 37, 1989.

Lewis, R. V., Freeman, M. P., and Reeves, G. D.: The relationship of HF radar backscatter to the accumulation of open magnetic flux prior to substorm onset, J. Geophys. Res., 103, $26613,1998$.

Lindqvist, P.-A. and Mozer, F. S.: The average tangential electric field at the noon magnetopause, J. Geophys. Res., 95, 17 137, 1990.

Lockwood, M., Sandholt, P. E., and Cowley, S. W. H.: Dayside auroral activity and magnetic-flux transfer from the solar-wind, Geophys. Res. Lett. 16, 33, 1989.

Lockwood, M. and Davis, C. J.: On the longitudinal extent of magnetopause reconnection pulses, Ann. Geophysicae, 14, 865, 1996.

Lockwood, M.: Relationship of dayside auroral precipitations to the open-closed separatrix and the pattern of convective flow, J. Geophys. Res., 102, 17 475, 1997.

Maynard, N. C., Denig, W. F., and Burke, W. J.: Mapping ionospheric convection patterns to the magnetosphere, J. Geophys. Res., 100, 1713, 1995.

Moen, J., Sandholt, P. E., Lockwood, M., Egeland, A., and Fukui, K.: Multiple, discrete arcs on sunward convecting field lines in the 14-15 MLT region, J. Geophys Res., 99, 6113, 1994.

Neudegg, D. A., Yeoman, T. K., Cowley, S. W. H., Provan, G., Haerendel, G., Baumjohann, W., Auster, U., Fornaçon,K. H.,
Georgescu, E., and Owen, C. J.: A flux transfer event observed at the magnetopause by the Equator-S spacecraft and in the ionosphere by the CUTLASS HF radar, Ann. Geophysicae, 17, 707, 1999.

Newell, P. T. and Meng, C.-I.: Dipole tilt effects on the latitude of the cusp and cleft/low latitude boundary layer, J. Geophys. Res., 94, 6949, 1989.

Newell, P. T. and Meng, C.-I.: Ion acceleration at the equatorward edge of the cusp: Low altitude observations of patchy merging, Geophys. Res. Lett. 18, 1829, 1991.

Newell, P. T. and Meng, C.-I.: Mapping the dayside ionosphere to the magnetosphere according to particle precipitation characteristics, Geophys. Res. Lett. 19, 609, 1992.

Newell, P.T ., Feldstein, Y. I., Galperin, Y. I., and Meng, C.-I.: The morphology of nightside precipitation, J. Geophys. Res., 101, 10737, 1996.

Nishida, A. and Maezawa, K.: Two basic modes of interaction between the solar wind and the magnetosphere, J. Geophys. Res. 76, 2254, 1971.

Phan T. D., Kistler, L. M., Klecker, B., Haerendel, G., Paschmann, G., Sonnerup, B. U. O., Baumjohann, W., Bavassano-Cattaneo, M. B., Carlson, C. W., Dilellis, A. M., Fornacon, K. H., Frank, L. A., Fujimoto, M., Georgescu, E.,Kokubun, S., Moebius, E., Mukai, T., Oieroset, M., Paterson, W. R., and Reme, H.: Extended magnetic reconnection at the Earth's magnetopause from detection of bi-directional jets, Nature, 404, 848, 2000.

Phan, T. D., Freeman, M. P., Kistler, L. M., Klecker, B., Haerendel, G., Paschmann, G., Sonnerup, B. U. O., Baumjohann, W., Bavassano-Cattaneo, M. B., Carlson, C. W., Dilellis, A. M., Fornacon, K. H., Frank, L. A., Fujimoto, M., Georgescu, E., Kokubun, S., Möbius, E., Mukai, T., Paterson, W. R., and Rème, H.: Evidence for an extended reconnection line at the dayside magnetopause, Earth Planets and Space, 53, 619, 2001.

Pinnock, M., Rodger, A. S., Dudeney, J. R., Baker, K. B., Newell, P. T., Greenwald, R. A. and Greenspan, M. E.: Observations of an enhanced convection channel in the cusp ionosphere, J. Geophys. Res., 98, 3767, 1993.

Pinnock, M., Rodger, A. S., Dudeney, J. R., Rich, F., and Baker, K. B.: High spatial and temporal resolution observations of the ionospheric cusp, Ann. Geophysicae, 13, 919, 1995.

Pinnock, M., Rodger, A. S., Baker, K. B., Lu, G., and Hairston, M.: Conjugate observations of the day-side reconnection electric field: A GEM boundary layer campaign, Ann. Geophysicae, 17, 443, 1999.

Pinnock, M. and Rodger, A. S.: On determining the noon polar cap boundary from SuperDARN HF radar backscatter characteristics, Ann. Geophysicae, 18, 1523, 2001.

Provan, G. and Yeoman, T. K.: Statistical observations of the MLT, latitude and size of pulsed ionospheric flows with the CUTLASS Finland radar, Ann. Geophysicae, 17, 855, 1999.

Provan, G., Yeoman, T. K., Milan, S. E., Ruohoniemi, J. M., and Barnes, R.: An assessment of the map-potential and beamswinging techniques for measuring the ionospheric convection pattern using data from the SuperDARN radars, Ann. Geophysicae, 20, 191, 2002.

Reiff, P. H., Spiro, R. W., and Hill, T. W.: Dependence of polar-cap potential drop on inter-planetary parameters, J. Geophys. Res., 86, 7639, 1981.

Ridley, A. J., Lu, G., Clauer, C. R., and Papitashvili, V. O.: Ionospheric convection during non-steady interplanetary magnetic field conditions, J. Geophys. Res., 102, 14 563, 1997.

Ridley, A. J., Lu, G., Clauer, C. R., and Papitashvili, V. O.: A statis- 
tical study of the ionospheric convection response to changing interplanetary magnetic field conditions using the assimilative mapping of ionospheric electrodynamics technique, J. Geophys. Res., 103, 4023, 1998.

Rodger, A. S. and Pinnock, M.: The ionospheric response to flux transfer events: The first few minutes, Ann. Geophysicae, 15, 685, 1997.

Rodger, A. S.: Ground-based imaging of magnetospheric boundaries. Advances in Space Research, 25, No. 7-8, 1461, 2000.

Roelof, E. C. and Sibeck, D. G.: Magnetopause shape as a bivariate function of interplanetary magnetic-field $B_{z}$ and solar-wind dynamic pressure, J. Geophys. Res., 98, 21 421, 1993.

Russell, C. T. and Elphic, R. C.: ISEE observations of flux transfer events on the dayside magnetopause, Geophys. Res. Lett., 6, 33, 1979.

Ruohoniemi, J. M., Greenwald, R.A., Baker, K. B., and Villain, J.P.: Drift motions of small-scale irregularities in the high-latitude F-region: An experimental comparison with plasma drift motions, J. Geophys. Res., 92, 4553, 1987.

Ruohoniemi, J. M. and Greenwald, R. A.: Statistical patterns of high-latitude convection obtained from Goose Bay HF radar observations, J. Geophys. Res., 101, 21 743, 1996.

Ruohoniemi, J. M. and Baker, K. B.: Large-scale imaging of highlatitude convection with Super Dual Auroral Radar Network HF radar observations, J. Geophys. Res., 103, $20797,1998$.

Sandholt, P. E., Farrugia, C. J., Øieroset, M., Stauning, P., and Denig, W. F.: Auroral activity associated with unsteady magnetospheric erosion: Observations on December 19, 1990, J. Geophys. Res., 103, 2309, 1998.

Shepherd, S. G. and Ruohoniemi, J. M.: Electrostatic potential patterns in the high-latitude ionosphere constrained by SuperDARN measurements, J. Geophys. Res., 105, 23 005, 2000.

Shue, J. H., Song, P., Russell, C. T., Thomsen, M. F., and Petrinec, S. M.: Dependence of magnetopause erosion on southward interplanetary magnetic field, J. Geophys. Res., 106, 18 777, 2001.

Sonnerup, B. U. O., Paschmann, G., G. Papamastorakis, G., Sckopke, N., Haerendel, G., Bame, S. J., Asbridge, J. R., Gosling, J. T., and Russell, C. T.: Evidence for magnetic-field reconnection at the earths magnetopause, J. Geophys. Res., 86, 49, 1981.

Southwood, D. J., Farrugia, C. J., and Saunders, M. A.: What are flux-transfer events, Planet. Space Sci., 36, 503, 1988.

Tsyganenko, N. A.: Effects of the solar wind conditions on the global magnetospheric configuration as deduced from data-based field models, in: Proceedings of the ICS-3 Conference on Substorms, Eur. Space Agency Spec. Publ., ESA SP-389, 181, 1996.

Tsyganenko, N. A.: Modeling the Earth's magnetospheric magnetic field confined within a realistic magnetopause, J. Geophys. Res., 100, 5599, 1995.

Tsyganenko, N. A. and Stern, D. P.: Modelling the global magnetic field of large-scale Birkeland current systems, J. Geophys. Res., 101, 27 187, 1996.

Villain, J.-P., Caudal, G., and Hanuise, C.: A SAFARI-EISCAT comparison between the velocity of $\mathrm{F}$ region small-scale irregularities and the ion drift, J. Geophys. Res., 90, 8433, 1985.

Weimer, D. R.: Models of high-latitude electric potentials derived with a least error fit of spherical harmonic coefficients, J. Geophys. Res., 100, 19595, 1995.

Yeoman, T. K., Lewis, R. V., Milan, S. E., and Watanabe, M.: An interhemispheric study of the ground magnetic and ionospheric electric fields during the substorm growth phase and expansion phase onset, J. Geophys. Res., 104, 14 867, 1999. 